\title{
FACTORS ASSOCIATED WITH REACTIONAL STATES IN LEPROSY WITH SPECIAL REFERENCE TO MALARIA
}

\author{
by R. E. Pfaltzgraff, m.D., Garkida Leprosarium, N. Nigeria
}

During several years of treating patients with leprosy we noticed an apparent relationship between intercurrent disease and the occurrence of reactional states. Since there seems to be very little reference to this relationship in the literature, we attempted a statistical analysis of this relationship by examining all the instances of recorded reactions occurring in the patients in the Garkida Leprosarium during the eight-year period beginning 1st January, 1951. The census of patients under care varied considerably during these years (see appended Table). The fluctuation was chiefly in milder cases, and the total number of severe tuberculoid, dimorphous and lepromatous cases, namely those who would be likely to suffer reactions, would not have been significantly different in the various years.

In this study all reactional conditions presumed to be associated with leprosy were included in the records; thus including lepra reaction, erythema nodosum leprosum, neuritis, iritis, etc. All attendances at the dispensary for reactional states were recorded except where a patient complained more than once in a month, when it was presumed that it may have been the same reaction. However, if a patient called again in a succeeding month he was counted again. Thus for a continuous reactional state a patient would be counted once monthly until cessation of the reaction.

It will be noted in the Table that there is an increase of reactions during the times when there have been epidemics of chickenpox and measles, as well as during the month in which a large number of the patients were immunized against smallpox and developed vaccinia ${ }^{1}$.

The most significant of our findings is the marked increase in the number of reactions coming on during the rainy season which occurs here during the months of July, August and September. The incidence of malaria is also highest during these months and October. Thus it was postulated that perhaps the malaria was a precipitating factor in reactional states, and we decided to determine the effect of malarial suppression using pyrimethamine (Daraprim) $25 \mathrm{mgm}$. weekly during the months of July, August and September, during 1955, 1956 and 1957. This caused an immediate drop in the number of reactions per month during the time of year when they had previously been the highest ${ }^{2}$. In 1958 no malarial suppression was attempted, and the number of reactions per month again rose during the months of high malarial prevalence. 
INCIDENCE OF REACTIONAL STATES IN LEPROSY

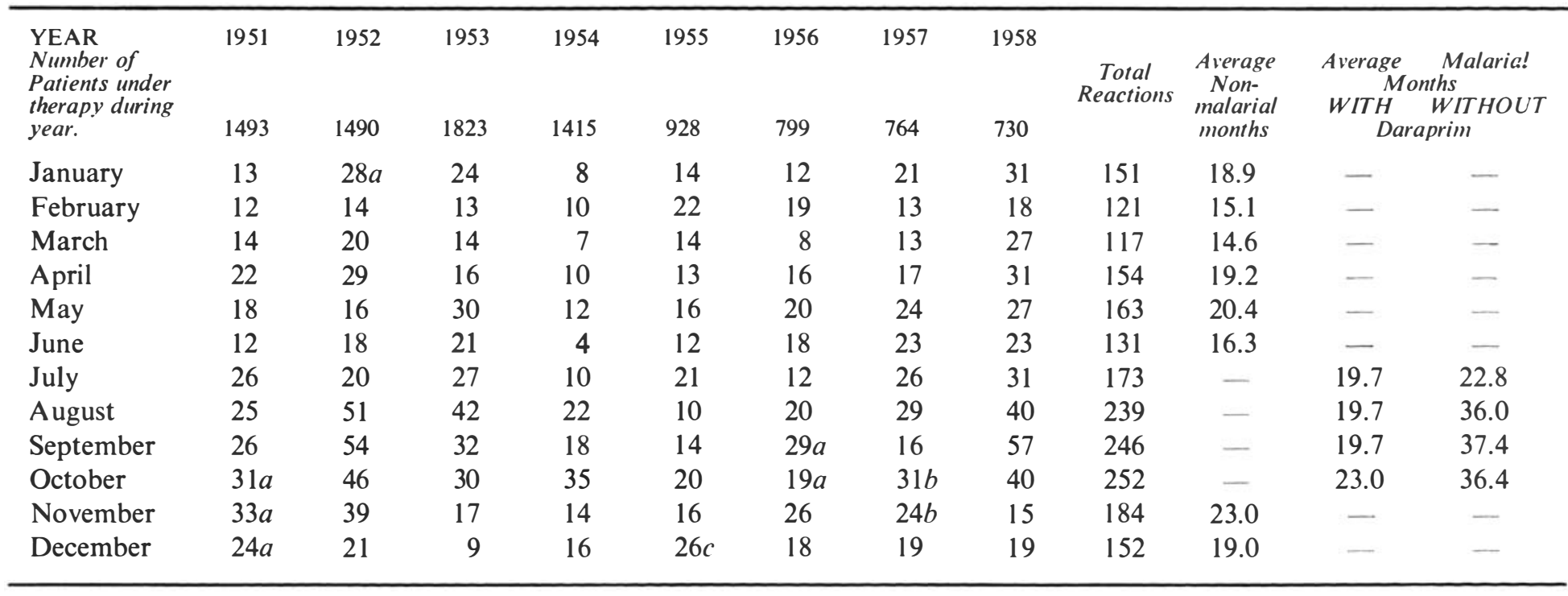

TOTA L REACtIONS 2,083

(a) Months in which there was "epidemic" chickenpox.

(c) Smallpox in which there was "epidemic" measles. Average Malarial Months with Daraprim-20.6. 
Thus we have shown that during those months when malarial transmission is minimal there was an average of 18.3 reactions per month; whereas, in the four months when malaria is prevalent and we did not administer pyrimethamine, the average number of reactions was 33.1 ; and during the four months during the three years when pyrimethamine was given the average number of reactional states was 20.6. Our clinical impression also was that during 1958 when we did not again give pyrimethamine, in spite of improved methods of treatment, especially the use of cortisone and its derivatives, the severity and persistence of reactions were considerably greater than during the three preceding years when pyrimethamine was used.

Thus we suggest that malarial suppression during the months of highest malarial incidence, using pyrimethamine once weekly in $25 \mathrm{mgm}$. dosage, is of definite value in reducing the number of reactional states occurring in leprosy patients who have those types of disease prone to develop reactional states.

\section{Summary}

1. Intercurrent infections are important factors in the inciting of reactional states in leprosy.

2. The wide endemicity of malaria in the tropics makes it an especially important inciting disease.

3. Malarial suppression with pyrimethamine has proved of significant value in reducing the incidence of reactional states in leprosy.

\section{References}

1. Webster, I. M. "The Response of Leprosy Patients to Smallpox Vaccine." Report to West African Medical Research Council, Nigeria, 18th Feb. 1959.

2. Bruce-Chwatt, L. J. and Horn, D. W. "Antimalarial Drugs in Nigeria." Brit. Med. Journ., (Oct. 1958) 5101, 869-876. 